\title{
Neurophysiological functioning of occasional and heavy cannabis users during THC intoxication
}

\author{
Eef L. Theunissen • Gerold F. Kauert • Stefan W. Toennes • Manfred R. Moeller • \\ Anke Sambeth • Mathieu M. Blanchard • Johannes G. Ramaekers
}

Received: 21 April 2011 /Accepted: 31 August 2011 /Published online: 6 October 2011

(C) The Author(s) 2011. This article is published with open access at Springerlink.com

\begin{abstract}
Rationale Experienced cannabis users demonstrate tolerance to some of the impairing acute effects of cannabis.

Objectives The present study investigates whether eventrelated potentials (ERPs) differ between occasional and heavy cannabis users after acute $\Delta^{9}$-tetrahydrocannabinol (THC) administration, as a result of tolerance.

Methods Twelve occasional and 12 heavy cannabis users participated in a double-blind, placebo-controlled, crossover study. On two separate days, they smoked a joint containing 0 or $500 \mu \mathrm{g} / \mathrm{kg}$ body weight THC. ERPs were measured while subjects performed a divided attention task (DAT) and stop signal task (SST).

Results In the DAT, THC significantly decreased P100 amplitude in occasional but not in heavy cannabis users. P300 amplitude in the DAT was significantly decreased by
\end{abstract}

E. L. Theunissen $(\bowtie) \cdot$ A. Sambeth $\cdot$ J. G. Ramaekers

Department of Neuropsychology and Psychopharmacology,

Faculty of Psychology and Neuroscience, Maastricht University,

P.O. Box 616, 6200MD Maastricht, The Netherlands

e-mail: e.theunissen@maastrichtuniversity.nl

G. F. Kauert • S. W. Toennes

Department of Forensic Toxicology, Institute of Legal Medicine,

Goethe University of Frankfurt,

Frankfurt, Germany

M. R. Moeller

Unikliniken des Saarlandes,

Homburg, Germany

M. M. Blanchard

Department of Pharmacology, Faculty of Medicine,

Dalhousie University,

Halifax, Canada
THC in both groups. The N200 peak in the SST was not affected by treatment in neither of the groups. Performance in the SST was impaired in both groups after THC treatment, whereas performance in the DAT was impaired by THC only in the occasional users group.

Conclusions The present study confirms that heavy cannabis users develop tolerance to some of the impairing behavioral effects of cannabis. This tolerance was also evident in the underlying ERPs, suggesting that tolerance demonstrated on performance level is not (completely) due to behavioral compensation.

Keywords Cannabinoids · Cognition · Psychomotor performance $\cdot$ Event-related potentials $\cdot$ Tolerance

Cannabis is the most frequently used illicit drug in the Western world, with estimates going up to $18 \%$ of Europeans having tried cannabis at least once in their life (Rigter and van Laar 2002). The widespread use of cannabis and its potential for increased therapeutic use have given rise to significant public health concern, mostly regarding the effects of cannabis on cognition and psychomotor function.

The acute effects of $\Delta^{9}$-tetrahydrocannabinol (THC), the major psychotropic compound in cannabis, on cognitive and psychomotor performance have been assessed in numerous experimental studies using within-subject, double-blind, placebo-controlled designs. These have generally shown that THC in doses between 40 and $300 \mu \mathrm{g} / \mathrm{kg}$ causes a dose-dependent reduction in performance at tests measuring memory, attention, reaction time (RT), tracking, and motor function (Curran et al. 2002; Hall and Solowij 1998; Heishman et al. 1997). This performance impairment after acute THC administration was shown to be highest 
during the first hour after smoking or between 1 and $2 \mathrm{~h}$ after oral intake (Curran et al. 2002). The number of significant performance effects sharply declined to about zero over 3-4 $\mathrm{h}$ after THC use.

It has been demonstrated that frequency and history of cannabis use can affect the performance outcome. In a study by Pope and Yurgelun-Todd (1996), heavy cannabis users (smoking approximately daily) showed significantly greater impairment than light users (smoking on average once a month) on attentional and executive functions after a minimum of $19 \mathrm{~h}$ abstinence. In another study by Pope et al. (2001), current heavy users (smoked $>5,000$ times and smoking daily) demonstrated cognitive impairment up to 7 days after last cannabis use. This impairment was related to levels of carboxy-THC in urine and was no longer present after 28 days of abstinence. Bolla et al. (2002) did demonstrate impairment after 28 days of abstinence in very heavy cannabis users (smoking approximately 35 joints/ week), but found no relation with duration of use. In a longitudinal study, Fried et al. (2002) compared IQ scores of light ( $<5$ joints/week) and heavy ( $\geq 5$ joints/week) current users, former users, and nonusers. These IQ scores were compared with the subjects' IQ scores that were obtained before initiation of drug use. Fried et al. (2002) found that current marijuana users showed a lower overall IQ, but only in the heavy users group. The former heavy users, who had not used in at least 3 months, showed no decline in IQ score. Therefore, it can be concluded that impairment is apparent in current regular users, even when they are not in an intoxicated state, but that this impairment is not permanent if they stop using (Fried et al. 2002).

From these studies, it can be concluded that cognitive impairments can be demonstrated in cannabis users up to a couple of days after their last use and that this impairment is related to the duration and frequency of use. However, none of these studies have looked at the effect of frequency or duration of use on the acute effects of cannabis.

As with other drugs, regular cannabis use induces tolerance for the acute effects. Previous studies have demonstrated that frequent use of low doses of cannabis can rapidly induce tolerance for the subjective high of cannabis (Cappell and Pliner 1974; Jones et al. 1981). Hart et al. (2001) also demonstrated that heavy cannabis users showed only minimal impairment on complex cognitive tasks after acute cannabis administration. However, it is hard to draw conclusions from this study, as an infrequent cannabis user group was not included. Furthermore, the lack of impairment may be due to the fact that subjects were still impaired in the placebo condition as a result of residual effects. In addition, the exact dose of administered THC was not reported, nor were plasma THC concentrations provided (Nordstrom and Hart 2006; Ramaekers et al. 2006).
We recently investigated neurocognitive performance in heavy (using cannabis $>4$ times/week) and occasional cannabis users (using cannabis $<2$ times/week) during acute intoxication (Ramaekers et al. 2009). In this placebocontrolled study, a high dose of THC $(500 \mu \mathrm{g} / \mathrm{kg})$ was administered, while performance measures were conducted four times between 0 and $8 \mathrm{~h}$ after smoking. This study demonstrated that the acute effect of THC on human performance is dependent on cannabis use history. Occasional users showed impairments in all performance tasks (i.e., tracking, divided attention task [DAT], and stop signal task [SST]) after smoking cannabis. Heavy users only demonstrated impairment in one performance parameter (i.e., impulse control as measured in the SST) and only at THC concentration above $10 \mathrm{ng} / \mathrm{ml}$ in serum. This suggests that heavy cannabis users develop tolerance for some of the impairing effects of cannabis. While this may be the result of pharmacological adaptations, it may also be due to behavioral compensatory mechanisms. Therefore, the behavioral performance of subjects might not be a good indicator for the effect of drugs on brain functioning. Previous studies, using positron emission tomography and functional magnetic resonance imaging, have demonstrated differences in brain activity in heavy current users and 25-day abstinent heavy users, despite a lack of performance differences (Eldreth et al. 2004; Kanayama et al. 2004). These studies suggest that experienced abstinent users draw on alternative neural networks in order to compensate for the impairment caused by THC.

Event-related potentials (ERPs) are well suited to investigate brain functioning directly. Few studies have examined the effects of cannabis on ERP measures. A consistent finding in those ERP studies is that P300 amplitude is decreased in acutely intoxicated cannabis users (Böcker et al. 2010; Ilan et al. 2004, 2005; Roser et al. 2008) and in cannabis users who are not under the influence of the drug at that time (Kempel et al. 2003; Solowij et al. 1991). The P300 component has previously been shown to reflect attentional resource allocation and working memory (Kok 2001; Polich and Kok 1995). ERPs after acute THC administration are even scarcer. In a single case study, Solowij et al. (1995) showed that acute THC administration after 6 weeks of abstinence normalized the ERP (processing negativity) of a heavy cannabis user during selective attention.

The aim of the present study is to assess ERP measures during THC intoxication in occasional and heavy cannabis users. This will elucidate whether tolerance to the impairing effects of THC can be demonstrated at the neurophysiological level, as has been shown at the behavioral level in heavy cannabis users. This study was part of a larger study of which the results are already published (Ramaekers et al. 2009) and involves the same subjects. 


\section{Methods}

Subjects

All participants were used to smoking cannabis in combination with tobacco. Twelve occasional cannabis users [8 males and 4 females; mean age 22.8 years $( \pm 2.3)$ ] and 12 heavy users [ 9 males and 3 females; mean age 23.2 years $( \pm 3.3)$ ] were included in this study. A summary of the participants' demographics and drug use characteristic is given in Table 1. Independent-samples $t$ tests showed that there were no differences between groups, except of course on cannabis use per year.

Subjects were recruited through advertisements in coffee shops and at the university site. A first screening consisted of a medical and drug questionnaire. Heavy users were selected when smoking more than four times a week, while the occasional group consisted of users that smoked less than twice a week. Selected subjects were subsequently examined by a medical supervisor who checked vital signs and took blood and urine samples. Standard blood chemistry, hematology, and drug screen tests were performed on these samples. Inclusion criteria were free from psychotropic medication; good physical health as determined by the medical examination and laboratory analysis; absence of any major medical, endocrine, and neurological condition; body mass index between 18 and $28 \mathrm{~kg} / \mathrm{m}^{2}$; and written informed consent. Exclusion criteria were any history of drug abuse or addiction (other than cannabis); pregnancy or lactation or failure to use reliable contraceptive; excessive drinking ( $>20$ alcoholic consumptions a week); excessive smoking ( $>25$ cigarettes/day); hyperten- sion (diastolic $>100$; systolic $>170$ ); presence or history of a psychiatric illness; color blindness; or dyslexia.

The study was approved by the Ethics Committee of Maastricht University Hospital and conducted according to the World Medical Associations Declaration of Helsinki (Edinburgh modification 2000). A permit for obtaining, storing, and administering marijuana was obtained from the Dutch drug enforcement administration. All subjects received financial compensation for their participation.

Design, doses, and administration

The study was conducted according to a double-blind, placebo-controlled, two-way crossover design. Subjects received placebo and $500 \mu \mathrm{g} / \mathrm{kg}$ body weight THC on two separate test days. Subjects were told that they would receive different doses of THC on separate test days. There was a minimum period of 7 days between treatments. Smoking occurred in the morning of test days. The cigarettes were prepared beforehand for each individual. Cannabis stock was provided by the Dutch Bureau for Medicinal Cannabis and contained 13\% THC. The total weight of the cigarette was $0.8 \mathrm{~g}$, containing tobacco and $500 \mu \mathrm{g} / \mathrm{kg}$ body weight THC. This lead to an average cannabis content of $0.256 \mathrm{~g}$ for the heavy users group and $0.277 \mathrm{~g}$ for the occasional users group. Placebo cigarettes contained $0.8 \mathrm{~g}$ of tobacco. Participants were instructed to smoke the cigarette according to a fixed procedure in order to minimize the subject's possibility of dose titration and to increase optimal absorption of THC (Robbe 1994), i.e., inhale for $4 \mathrm{~s}$, hold breath for $10 \mathrm{~s}$, and exhale/brake for $15 \mathrm{~s}$. This was repeated until the cigarettes were smoked as

Table 1 Subject demographics (mean, SD) and history of drug use in heavy and occasional cannabis users

\begin{tabular}{|c|c|c|c|c|}
\hline & \multicolumn{2}{|l|}{ Heavy } & \multicolumn{2}{|l|}{ Occasional } \\
\hline$N$ & 12 & & 12 & \\
\hline Age (years) & $23.2(3.3)$ & & $22.8(2.3)$ & \\
\hline Weight (kg) & $66.6(8.4)$ & & $71.9(16.6)$ & \\
\hline Cannabis use (times)/year & $340(86)$ & & $55(36)$ & \\
\hline Joints per occasion & $2.3(1.2)$ & & $1.2(0.5)$ & \\
\hline Years of cannabis use & $6.2(3.4)$ & & $7.4(2.7)$ & \\
\hline Alcoholic drinks/week & $7.4(7.4)$ & & $8.5(6.6)$ & \\
\hline Number of regular tobacco users & 8 & & 6 & \\
\hline Mean number cigarettes/day & $6.25(4.3)$ & & $6.17(6.6)$ & \\
\hline Number of subjects having used & During previous year & $\begin{array}{l}\text { Mean frequency of use } \\
\text { in previous year }\end{array}$ & During previous year & $\begin{array}{l}\text { Mean frequency of use } \\
\text { in previous year }\end{array}$ \\
\hline Ecstasy & 2 & 4 & 42 & 1.5 \\
\hline Amphetamine & 0 & & 21 & 1 \\
\hline Cocaine & 4 & 1.7 & 21 & 1 \\
\hline Mushrooms & 41 & 1 & 72 & 1.5 \\
\hline
\end{tabular}


completely as possible and took 10 to 15 min. Mean (SD) number of puffs smoked from the placebo and THC cigarette was $25(6.4)$ and 28 (15.4) for the occasional users and 22 (7.5) and 22 (8.2) for the heavy users, respectively.

\section{Procedures}

All participants were asked to refrain from any drug (except cannabis) use during the entire study. The occasional users were asked not to use cannabis for a minimum of 5 days prior to each test day, while the heavy users were to continue using cannabis according to their normal routine. Alcohol was not allowed $24 \mathrm{~h}$ prior to each test day and caffeine was not allowed on a test day. Participants were asked to arrive at the site well rested. Drug screens (Mahsan Kombi DOA6+ urine drug test) and alcohol breath analyses were performed upon arrival of the subjects, screening for the presence of alcohol, THC, opiates, amphetamine, cocaine, methamphetamine, and benzodiazepines. For occasional users, administration of the placebo or THC cigarette was only continued if drug and alcohol tests were negative. In case of a positive drug test, subjects were sent home and their test day was rescheduled. For the heavy users, administration of the cigarette (THC or placebo) was only continued if they were positive for THC, but negative for other drugs and alcohol.

Prior to the first test session, subjects received training in order to familiarize them with the tests and procedures and minimize practice effects. On test days, subjects received a standard breakfast prior to smoking. The performance tasks and ERP registration began 20 min after smoking.

\section{ERP measures during task performance}

An electro-cap with 30 tin electrodes was used to record EEG activity (standard 10-20 system; Fz, Cz, Pz, Oz, F3, F4, F7, F8, C3, C4, T3, T4, T5, T6, P3, P4, O1, O2, Fp1, Fp2, Ft7, Ft8, Fc3, Fc4, Tp7, Tp8, Cp3, Cp4, FCz, CPz). Electrodes were filled with electro-gel. All electrodes were referenced to the left mastoid; $\mathrm{FPz}$ was used as ground electrode. Horizontal EOG was recorded using electrodes attached to the outer canthi of the eyes, while vertical EOG was recorded from infraorbital and supraorbital electrodes placed in line with the pupil of the left eye. All electrode impedances were kept below $5 \mathrm{k} \Omega$. ERPs were collected using the Neuroscan 4.3 software, and SynAmps amplifiers were used. All signals were continuously sampled at a rate of $1,000 \mathrm{~Hz}$ and digitally filtered online with a high-pass filter of $0.10 \mathrm{~Hz}$ and a low-pass filter of $100 \mathrm{~Hz}$. Offline continuous signals were epoched into $1,200 \mathrm{~ms}$ sweeps including a 200-ms prestimulus baseline. All of the sampled EEG and EOG epochs were baseline corrected and filtered offline using a $30-\mathrm{Hz}, 12 \mathrm{~dB} /$ oct digital lowpass filter. EEGs were corrected for horizontal and vertical eye movements according to a procedure by Semlitsch et al. (1986). Sweeps containing an artifact exceeding +75 or $-75 \mu \mathrm{V}$ were rejected.

\section{Performance tasks}

Divided attention task The DAT measures the ability to divide attention between two tasks performed simultaneously (Moskowitz 1973). The primary task measures the subjects' ability to control a displayed error signal in a first-order compensatory tracking task. Error is displayed as a horizontal deviation of a cursor from the midpoint on a horizontal, linear scale. Compensatory joystick movements null the error by returning the cursor to the midpoint. The difficulty of the task is set at a constant level of $50 \%$ of the subjects' maximum capacity, as determined in the training session. Tracking error is measured as the difference in millimeters between the average position of the cursor and the middle of the horizontal scale. In the secondary task, subjects monitor a central display upon which single digits are presented at 1-2 s intervals. The occurrence of the digit " 2 " is a signal for the subject to remove the foot from a pedal as rapidly as possible. In total, 75 targets and 375 nontargets were presented. Mean absolute tracking error (in millimeters) and number of control losses are the performance measures of the primary task. Number of correct detections and average RT (in milliseconds) are the dependent variables of the secondary task.

In the DAT, two ERP components were calculated, i.e., P100 and P300 (or P3b). P100 reflects early attentional processes and appears around $100 \mathrm{~ms}$ above the visual cortex (Mangun 1995; Mangun and Hillyard 1990). The P300, or P3b, has mostly been demonstrated in oddball tasks and appears between 300 and $800 \mathrm{~ms}$ in the parietal area (Polich and Kok 1995). It reflects attentional resource allocation and working memory and is affected by the probability of the rare stimulus in both passive and active tasks (Duncan-Johnson 1981; Mertens and Polich 1997; Polich and Kok 1995). The P300 component has also been shown to be an indicator for processing capacity in dual tasks (Brocke et al. 1996; Duncan-Johnson 1981; Isreal et al. 1980; Kok 2001; Smulders et al. 1995; Theunissen et al. 2004; Wickens et al. 1983).

In the present study, ERP averages for individual subjects were calculated for correct responses to targets and distracters of the secondary task of the DAT. Parietal (Pz) P300 peak amplitude and latency were determined in a window between 275 and $650 \mathrm{~ms}$ as a measure of the amount of invested capacity in the secondary task. Furthermore, the maximum P100 amplitude and latency at $\mathrm{Oz}$ were scored between 80 and $200 \mathrm{~ms}$ to examine the 
effects of primary task load on early attentional processing of stimuli in the secondary task.

Stop signal task The SST measures motor impulsivity, which is defined as the inability to inhibit a precued response. The current test was adapted from an earlier version of Fillmore et al. (2002). In this task, subjects are required to make quick key responses to visually presented go signals and to inhibit any response when a visual stop signal is suddenly presented. The go signals were four 1.5$\mathrm{cm}$ letters $(\mathrm{ABCD})$ presented one at a time in the center of a computer screen. Subjects were required to respond to each letter as quickly as possible by pressing one of two response buttons. One button is pressed to indicate that " $A$ " or " $C$ " appeared and the other to indicate that " $B$ " or "D" appeared. Letters are displayed for $500 \mathrm{~ms}$ and the computer screen was blank for $1.5 \mathrm{~s}$ interstimulus interval before the next letter was displayed. The test consisted of 192 trials in which each of the 4 letters were presented equally often. The stop signal occurred in half of the trials and consisted of a visual cue, i.e., "**, that appeared in one of the four corners of the screen. Subjects were required to withhold any response in case a stop signal was presented. Stop signals were presented 24 times at each of the 4 delays after the onset of a letter: 50, 150, 250, and $350 \mathrm{~ms}$. Trials always began with a 500-ms preparation interval in which a fixation point appeared on the center of the screen. Dependent variables are stop RT and response accuracy. Stop RT is calculated by subtracting the stop signal delay from the RT on go trials associated with $n$-th percentile of the RT distribution. The $n$-th percentile corresponds to the percentage of commission errors (not inhibited in stop trial; Logan 1994).

In the SST, the N200 was measured. The negative N200 peak occurs around $200 \mathrm{~ms}$ post-stimulus, predominantly in frontal areas, and is reported to be related to response inhibition (Falkenstein et al. 1999; Jodo and Kayama 1992). The N200 amplitude and latency were measured at $\mathrm{Fz}$ for correct responses to go trials and for correct inhibitions to the stop signal (four stop signal delays separately), as the minimal amplitude between 150 and $300 \mathrm{~ms}$ after the onset of the go signal or each stop signal. As the N200 is an indication of response inhibition, it is expected to be larger in stop conditions.

\section{Subjective high}

Directly after smoking and at 45 min post-smoking, a visual analog scale $(100 \mathrm{~mm})$ was used by the subject to rate their feeling of "high" as a percentage of the maximum ever experienced ( 0 indicating not high at all, 100 meaning maximally high).

\section{Pharmacokinetic assessments}

Blood samples $(6 \mathrm{ml})$ were taken by venipuncture at baseline, immediately after smoking, and every $15 \mathrm{~min}$ during the first hour after smoking. Samples were centrifuged after $30 \mathrm{~min}$ and the serum was frozen at $-20^{\circ} \mathrm{C}$ until analyses for pharmacokinetic assessments. THC, THC$\mathrm{COOH}$, and $\mathrm{OH}-\mathrm{THC}$ concentrations were determined using solid-phase extraction and gas chromatography with mass spectrometric detection with a limit of quantification of $0.5 \mathrm{ng} / \mathrm{ml}$ (for a more detailed description of the method, see Toennes et al. 2010).

\section{Data analyses}

Behavioral data were analyzed with a univariate ANOVA with the factors THC (two levels) and cannabis use history (two levels) and their interaction. All ERP parameters were normally distributed and analyzed using ANOVA with the within-subject factors THC (two levels) and stimulus (two levels for DAT and five levels for SST) and the betweensubject factor cannabis use history (two levels) and their interactions. All variables were tested two-tailed with a significance level $p<0.05$. A Pearson correlation was used to test the relation between behavioral measures, ERP measures, and THC concentrations. All statistical tests were conducted using SPSS (version 15).

\section{Results}

\section{Missing data}

Due to technical problems, one subject's foot responses (secondary task) were not registered during the DAT in the THC condition. One subject was not able to inhibit his responses in the SST; therefore, no ERPs could be calculated for this subject (occasional user in the THC condition). ERPs of the SST are also missing for one subject (heavy user in the THC condition), while ERP DAT data from three subjects (one heavy user and two occasional users; all in the THC condition) are missing due to technical malfunctioning.

\section{Subjective high}

Mean (SE) values for the subjective high for both groups and treatments are shown in Table 2. In both groups, subjective high was significantly increased immediately and $45 \mathrm{~min}$ after smoking THC $\left(F_{1,44}=47.08, p<0.000\right.$ and $F_{1,43}=44.81, p<0.000$, respectively). Immediately after smoking, subjective high ratings were also larger in the occasional users compared to heavy users in both THC and placebo condition $\left(F_{1,44}=7.13, p=0.011\right)$. 
Table 2 Summary of mean (SE) values of subjective high (immediately and 45 min after smoking) and performance measures in the DAT and SST for heavy and occasional cannabis users

\begin{tabular}{|c|c|c|c|c|c|c|c|}
\hline & \multicolumn{2}{|l|}{ THC } & \multicolumn{2}{|l|}{ Placebo } & \multirow[t]{2}{*}{ THC } & \multirow[t]{2}{*}{ History } & \multirow[t]{2}{*}{ THC $\times$ history } \\
\hline & Heavy & Occasional & Heavy & Occasional & & & \\
\hline Subjective high immediately after smoking (mm) & $54.4(7.9)$ & $76.8(8.1)$ & $9.75(3.9)$ & $24.9(7.4)$ & 0.000 & 0.011 & Ns \\
\hline Subjective high 45 min after smoking $(\mathrm{mm})$ & $55.5(8.8)$ & $68.3(7.7)$ & $8.8(3.6)$ & $19.9(7.5)$ & 0.000 & Ns & Ns \\
\hline \multicolumn{8}{|l|}{ DAT } \\
\hline Tracking error $(\mathrm{mm})$ & $17.5(1.9)$ & $18.5(1.1)$ & $17.0(1.8)$ & $13.5(1.2)$ & Ns & Ns & Ns \\
\hline Control losses (\#) & $6.3(2.4)$ & $39.9(16.5)$ & $4.7(2.7)$ & $0.8(0.4)$ & 0.020 & Ns & 0.032 \\
\hline Hits (\#) & $72.3(0.7)$ & $67.0(3.4)$ & $72.5(1.0)$ & $74.5(0.2)$ & 0.030 & Ns & 0.041 \\
\hline $\mathrm{RT}(\mathrm{ms})$ & $564.6(18.3)$ & $607.9(23.8)$ & $557.2(19.0)$ & $528.0(10.3)$ & 0.021 & Ns & 0.053 \\
\hline \multicolumn{8}{|l|}{ SST } \\
\hline Stop RT (ms) & $769.0(70.4)$ & $717.8(45.3)$ & $756.7(55.6)$ & $657.7(45.2)$ & 0.029 & Ns & Ns \\
\hline Accuracy (\#) & $90.8(1.0)$ & $81(7.2)$ & $90.8(1.2)$ & $91.8(0.9)$ & Ns & Ns & Ns \\
\hline
\end{tabular}

Ns not significant

\section{THC concentrations}

THC concentrations in serum were overall higher in heavy users compared to occasional users. Occasional users were negative for THC in the placebo condition, whereas heavy users were positive in the placebo condition and at baseline. A summary of the mean (SD) THC, THC-COOH, and $\mathrm{OH}-$ THC is given in Table 3.

Divided attention task

Mean (SE) values for performance on the DAT are given in Table 2. Behavioral measures of the DAT were significantly influenced by THC. THC increased the number of control losses $\left(F_{1,44}=5.812, p=0.02\right)$ and RT $\left(F_{1,43}=5.724, p=\right.$ $0.021)$ and decreased number of hits $\left(F_{1,43}=5.026, p=\right.$ $0.03)$. These effects were specific for the occasional users as indicated by a significant or nearly significant THC $\times$ cannabis use history interaction for the number of control losses $\left(F_{1,44}=4.900, p=0.032\right)$, RT $\left(F_{1,43}=3.945, p=\right.$ $0.053)$, and number of hits $\left(F_{1,43}=4.425, p=0.042\right)$.

P100 ERP analysis included 11 heavy users and 10 occasional users in the THC condition and all subjects in the placebo condition. Mean (SE) values of the ERPs from the DAT are given in Table 4. ERP P100 amplitude demonstrated a significant effect of stimulus $\left(F_{1,83}=6.956\right.$, $p=0.01)$ and THC $\times$ cannabis use history interaction $\left(F_{1,83}=\right.$

Table 3 Mean (SD) serum concentrations (in nanograms per milliliter) of THC, THC-COOH, and OH-THC as a function of time after smoking in occasional (THC condition only) and heavy users (THC and placebo condition)

\begin{tabular}{|c|c|c|c|c|c|c|}
\hline & \multicolumn{6}{|c|}{ Time after smoking (h) } \\
\hline & Baseline & 0.1 & 0.25 & 0.5 & 0.75 & 1.0 \\
\hline \multicolumn{7}{|l|}{ THC } \\
\hline Occasional (THC) & $0.0(0.0)$ & $49.1(24.9)$ & $20.7(9.3)$ & $13.3(5.3)$ & $10.9(4.4)$ & $8.5(3.3)$ \\
\hline Heavy (THC) & $3.4(3.5)$ & $120.9(78.1)$ & $47.4(28.2)$ & $30.3(18.6)$ & $22.6(12.2)$ & $19.0(10.5)$ \\
\hline Heavy (placebo) & $2.9(3.2)$ & $3.0(3.7)$ & $3.0(3.8)$ & $2.9(4.0)$ & $2.9(3.7)$ & $3.0(4.2)$ \\
\hline \multicolumn{7}{|l|}{ THC-COOH } \\
\hline Occasional (THC) & $1.6(0.5)$ & $12.0(11.8)$ & $10.5(12.0)$ & $9.5(11.1)$ & $8.5(10.3)$ & $7.5(9.1)$ \\
\hline Heavy (THC) & $71.0(79.0)$ & $107.3(95.8)$ & $114.8(96.2)$ & $114.9(92.3)$ & $113.9(92.6)$ & $102.5(85.4)$ \\
\hline Heavy (placebo) & $96.3(177.5)$ & $82.9(135)$ & $81.7(156.5)$ & $84.1(136.9)$ & $83.2(139.1)$ & $86.4(142.8)$ \\
\hline \multicolumn{7}{|l|}{ OH-THC } \\
\hline Occasional (THC) & $0.0(0.0)$ & $6.6(5.1)$ & $5.7(3.7)$ & $4.7(2.9)$ & $4.0(2.4)$ & $3.3(1.8)$ \\
\hline Heavy (THC) & $1.6(1.7)$ & $12.0(10.7)$ & $10.5(8.5)$ & $9.5(7.8)$ & $8.5(6.7)$ & $7.5(5.7)$ \\
\hline Heavy (placebo) & $1.9(3.1)$ & $1.9(3.3)$ & $1.7(2.8)$ & $1.9(3.1)$ & $1.8(2.8)$ & $1.7(2.9)$ \\
\hline
\end{tabular}


Table 4 Summary of mean (SE) values of the ERPs in the DAT and SST for heavy and occasional cannabis users

\begin{tabular}{|c|c|c|c|c|c|c|c|c|c|}
\hline & \multicolumn{2}{|l|}{ THC } & \multicolumn{2}{|l|}{ Placebo } & \multirow[t]{2}{*}{$\mathrm{THC}$} & \multirow[t]{2}{*}{ History } & \multirow[t]{2}{*}{ Stimulus } & \multirow[t]{2}{*}{ THC $\times$ history } & \multirow[t]{2}{*}{ THC $\times$ stimulus } \\
\hline & Heavy & Occasional & Heavy & Occasional & & & & & \\
\hline \multicolumn{10}{|l|}{ DAT } \\
\hline \multicolumn{5}{|c|}{ P100 amplitude $(\mu \mathrm{V})$} & \multirow[t]{3}{*}{ Ns } & \multirow[t]{3}{*}{ Ns } & \multirow[t]{3}{*}{0.01} & \multirow[t]{3}{*}{0.006} & \multirow[t]{3}{*}{ Ns } \\
\hline Distracters & $2.54(0.33)$ & $2.96(0.33)$ & $2.34(0.33)$ & $3.72(0.59)$ & & & & & \\
\hline Targets & $3.9(0.47)$ & $3.43(0.42)$ & $2.67(0.37)$ & $5.47(0.91)$ & & & & & \\
\hline \multicolumn{5}{|c|}{ P100 latency (ms) } & \multirow[t]{3}{*}{ Ns } & \multirow[t]{3}{*}{ Ns } & \multirow[t]{3}{*}{ Ns } & \multirow[t]{3}{*}{ Ns } & \multirow[t]{3}{*}{ Ns } \\
\hline Distracters & $145.6(6.4)$ & $138.8(8.0)$ & $138.7(6.4)$ & $145.7(6.6)$ & & & & & \\
\hline Targets & $139.8(6.5)$ & $139.3(7.0)$ & $138.2(6.7)$ & $147.6(6.4)$ & & & & & \\
\hline \multicolumn{5}{|c|}{ P300 amplitude $(\mu \mathrm{V})$} & \multirow[t]{3}{*}{0.003} & \multirow[t]{3}{*}{ Ns } & \multirow[t]{3}{*}{0.000} & \multirow[t]{3}{*}{ Ns } & \multirow[t]{3}{*}{0.014} \\
\hline Distracters & $0.67(0.4)$ & $0.61(0.5)$ & $0.81(0.4)$ & $1.1(0.3)$ & & & & & \\
\hline Targets & $4.17(1.1)$ & $3.19(0.4)$ & $6.1(1.1)$ & $8.42(1.7)$ & & & & & \\
\hline \multicolumn{5}{|c|}{ P300 latency (ms) } & \multirow[t]{3}{*}{ Ns } & \multirow[t]{3}{*}{ Ns } & \multirow[t]{3}{*}{ Ns } & Ns & Ns \\
\hline Distracters & $404.9(15.0)$ & $409.6(23.5)$ & $458.2(25.3)$ & $407.7(22.0)$ & & & & & \\
\hline Targets & $438.9(25.2)$ & $404.8(11.7)$ & $437.2(13.5)$ & $427.4(20.5)$ & & & & & \\
\hline SST & & & & & & & & & \\
\hline N200 ampli & ude $(\mu \mathrm{V})$ & & & & Ns & Ns & 0.000 & $\mathrm{Ns}$ & $\mathrm{Ns}$ \\
\hline Go & $0.88(0.9)$ & $2.09(1.3)$ & $0.06(0.7)$ & $2.50(0.6)$ & & & & & \\
\hline NoGo50 & $-2.38(1.2)$ & $-2.45(0.8)$ & $-3.39(0.5)$ & $-3.61(0.5)$ & & & & & \\
\hline NoGo150 & $-1.14(0.99)$ & $-0.79(1.3)$ & $-0.40(1.0)$ & $1.81(1.3)$ & & & & & \\
\hline NoGo250 & $-4.08(1.4)$ & $-5.29(0.9)$ & $-5.38(1.7)$ & $-8.27(1.3)$ & & & & & \\
\hline NoGo350 & $-8.58(1.0)$ & $-8.91(1.5)$ & $-7.98(1.0)$ & $-10.31(1.0)$ & & & & & \\
\hline N200 latency & (ms) & & & & Ns & $\mathrm{Ns}$ & 0.000 & $\mathrm{Ns}$ & $\mathrm{Ns}$ \\
\hline Go & $223.0(15.7)$ & $208.2(10.3)$ & $227.4(16.2)$ & $207.6(9.5)$ & & & & & \\
\hline NoGo50 & $250.2(13.4)$ & $250.5(12.5)$ & $253.3(15.4)$ & 229.7 (10) & & & & & \\
\hline NoGo150 & $334.8(9.0)$ & $366.6(14.7)$ & $359.7(16.0)$ & $354.9(9.5)$ & & & & & \\
\hline NoGo250 & $462.8(13.6)$ & $499.6(9.9)$ & $493.83(8.5)$ & $505.6(8.4)$ & & & & & \\
\hline NoGo350 & $579.9(13.0)$ & $594.4(14.0)$ & $582.7(8.5)$ & $589.2(10.8)$ & & & & & \\
\hline
\end{tabular}

Ns not significant

7.877, $p=0.006$ ). This interaction indicated that the occasional users showed a decrease in P100 amplitude when under the influence of THC, while in the heavy users, P100 increased when given THC compared to placebo (see Figs. 1 and 2). Separate paired-sample $t$ tests showed that the decrease in P100 in occasional users after THC was significantly different from placebo $(t(19)=-2,74, p=$ $0.013)$, while the increase in heavy users was not $(t(21)=$ $1,74, p=0.096)$. No effects were found for P100 latency in the DAT.

P300 ERP analysis included 11 heavy users and 10 occasional users in the THC condition and all subjects in the placebo condition. P300 amplitude revealed significant main effects of THC $\left(F_{1,83}=9.178, p=0.003\right)$, stimulus $\left(F_{1,83}=53.520, p=0.000\right)$, and $\mathrm{THC} \times$ stimulus interaction $\left(F_{1,83}=6.364, p=0.014\right)$. No effect of cannabis use history or interaction with cannabis use history was found. P300 amplitudes were largest for targets in the placebo condition (see Fig. 3).
Stop signal task

Mean (SE) values for performance on the SST are given in Table 2. The only behavioral SST measure that was significantly affected by THC is the stop RT. THC significantly increased stop RT $\left(F_{1,44}=5.123, p=0.029\right)$. No effect of history of drug use or interaction was found on the behavioral measures.

N200 No THC or cannabis use history effects were found on the SST frontal N200. A main effect of stimulus type was found on N200 amplitude $\left(F_{4,15}=56,491, p=0.000\right)$ and latency $\left(F_{4,15}=683,429, p=0.000\right)$, showing the largest and slowest N200 peaks for the stop trials with the longest delays. Mean (SE) values of the ERPs from the SST are given in Table 4.

Correlations

The stop RT in the SST was positively correlated with THC concentration measured before performance of the SST 

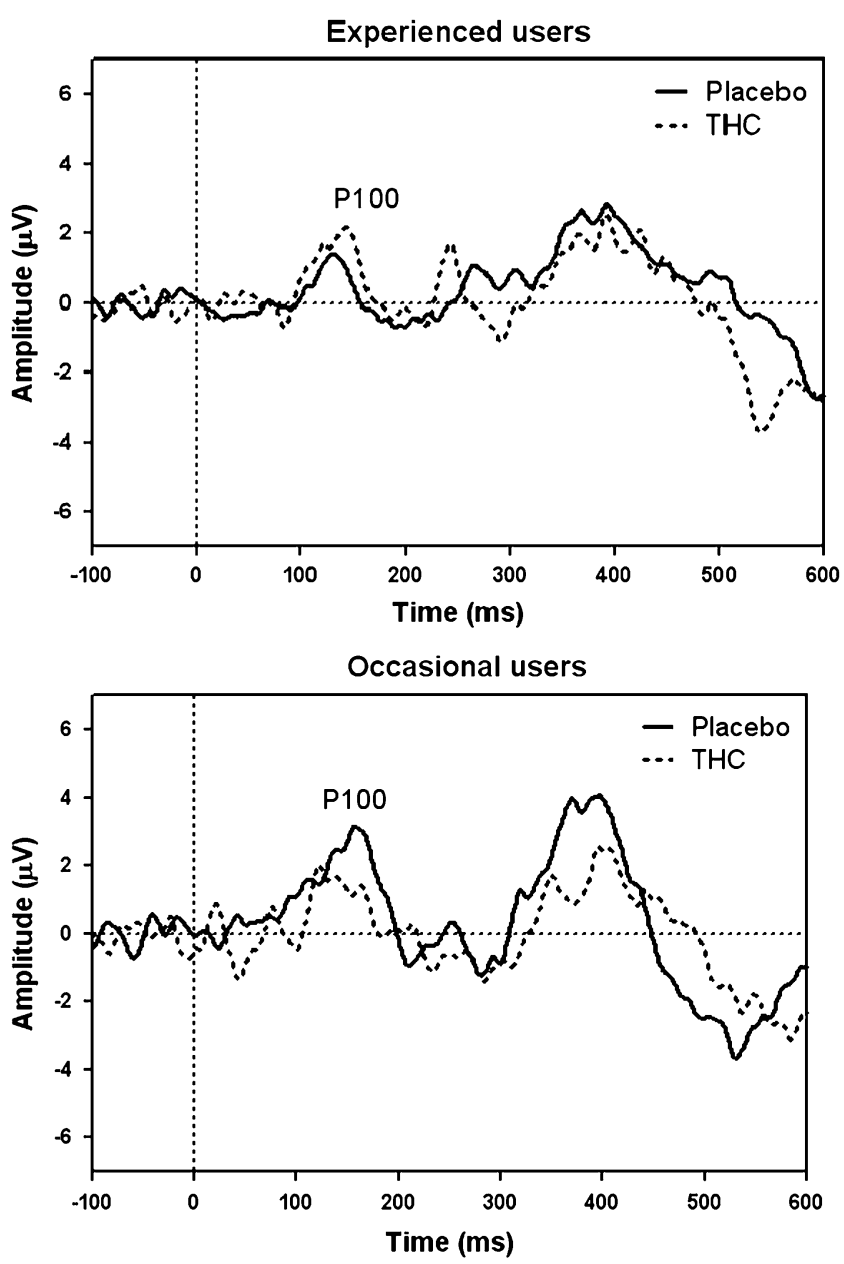

Fig. 1 Grand average ERP showing P100 at Oz for targets in the DAT. The upper panel shows ERPs of experienced users, while the lower panel shows that of occasional users

$(r(46)=0.37, p=0.012)$ and after completing the SST $(r(45)=$ $0.38, p=0.011)$. Other correlations between ERP measures,

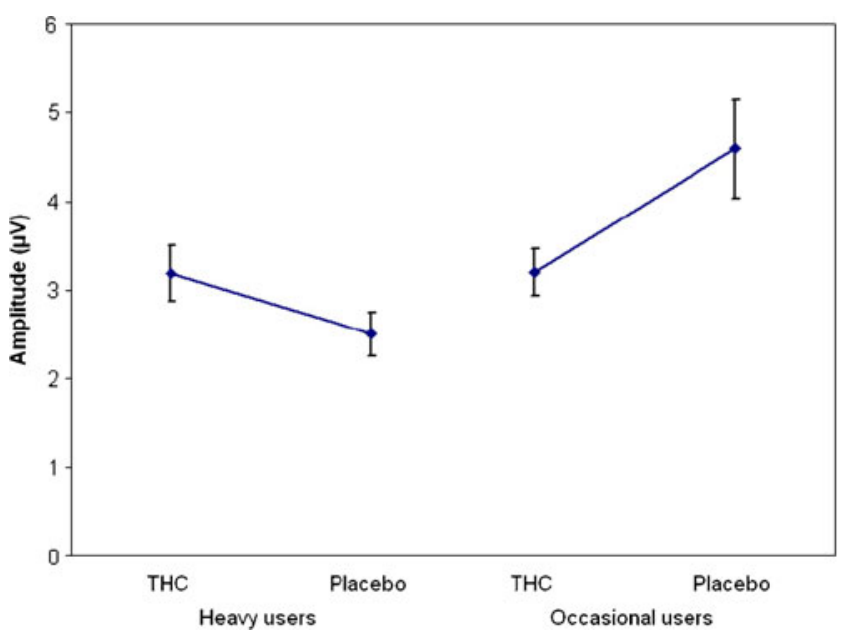

Fig. 2 Mean (SE) P100 (Oz) amplitude during the DAT for heavy and occasional users in the THC and placebo condition

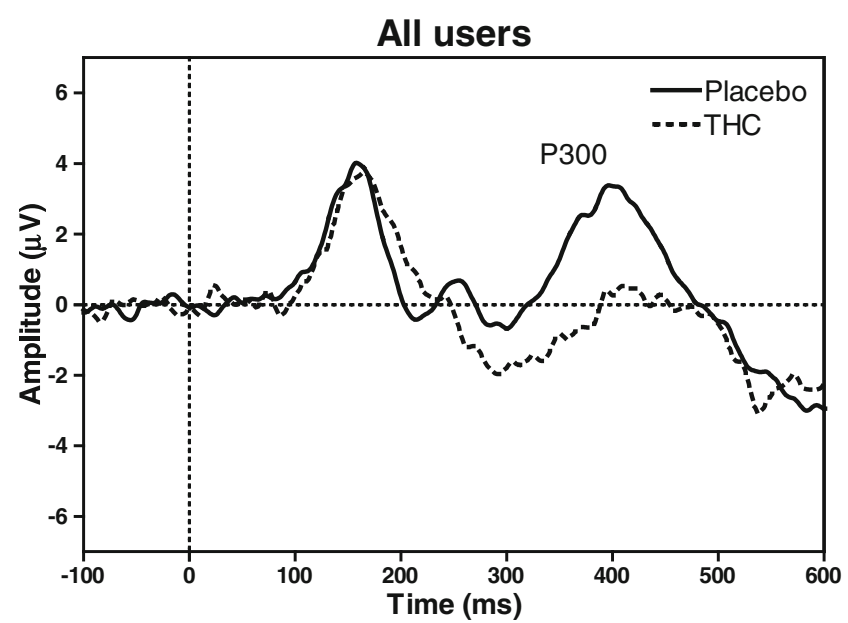

Fig. 3 Grand average ERP showing P300 at Pz for targets in the DAT of both groups of users together

behavioral results, subjective high, or THC concentrations were not significant.

\section{Discussion}

Previous studies have demonstrated that heavy cannabis users develop tolerance for the impairing effects of cannabis on cognitive performance. In the present study, we used ERPs to differentiate the information processes underlying the different performances of occasional and heavy cannabis users in cognitive tasks. The results of this study demonstrate that a drug use history by THC interaction was only present in the early P100 component which was measured during a DAT. In occasional users, the P100 amplitude was found to be decreased in the THC condition compared to the placebo condition. The P100 is thought to represent early attentional selection (Taylor 2002) and has been found to be enhanced when distracters are suppressed (Coull 1998). It could, therefore, be argued that, in the present study, the occasional cannabis users are less able to differentiate the targets from the distracters when under the influence of THC, and hence, their P100 is decreased. Since the heavy users do not demonstrate a change in P100 amplitude after THC administration, this could be an indication of tolerance to the effects of THC.

Cannabis also had an effect on the P300 of the DAT, i.e., amplitude was decreased after THC treatment. However, no interaction was found with drug use history. It thus seems that experienced users of THC were not tolerant to the effect of THC on P300. Previous studies using ERPs have also demonstrated that P300 is a robust measure of THC intoxication. Ilan et al. (2004) studied ERPs while subjects were in an intoxicated state. They showed that acute administration of a low dose of cannabis (3.45\% THC) 
impaired performance on a working memory task and an episodic memory task, while at the same time amplitudes of the related ERP components were decreased (N100, P200, P300, and N400). Although this study only included casual cannabis smokers (defined as using between once a month and once a week during the last year), the authors did notice that the degree of intoxication (measured by subjective high) influenced the ERP, in that the most intoxicated subject also showed the most decreased amplitudes. Recently, Böcker et al. (2010) concluded that ERP components related to selective attention were not influenced by high doses of cannabis (29.3, 49.2, and $69.4 \mathrm{mg}$ ), whereas amplitudes of components reflecting perceptual processing as well as stimulus classification (P300) were decreased. In this study, ERPs were measured $2 \mathrm{~h}$ after the administration of THC in regular nondaily users. These previous studies, together with the current results, demonstrate that P300 is a particular sensitive measure of THC-induced intoxication.

In the present study, no effects of THC for either of the groups were found on the ERP component of the SST, whereas the behavioral data did demonstrate increased stop RT in both heavy and occasional users. It is possible that the SST used is not well suited to elicit clear inhibition of ERPs. For instance, it included 96 go and 96 stop signals, which may be too little to elicit a clear and reliable N200. In our previous study, we demonstrated that heavy users only demonstrated impairment of impulse control in the SST when THC concentrations were above $10 \mathrm{ng} / \mathrm{ml}$ in serum. In the present study, we also demonstrated that THC concentration was positively related with stop signal RT, which measures impulse control.

The present data indicate that heavy cannabis users did not show tolerance to THC effects on subjective high. In addition, occasional cannabis users felt more high after THC than heavy users, although THC serum concentrations in heavy cannabis users were much higher than those observed in occasional users. A single dose of $500 \mu \mathrm{g} / \mathrm{kg}$ THC produced a mean peak concentration of $120.9 \mathrm{ng} / \mathrm{ml}$ in heavy cannabis users and $49.1 \mathrm{ng} / \mathrm{ml}$ in occasional users. Both groups were instructed to adhere to the same smoking protocol. On average, occasional and heavy users smoked 28 and 22 number of puffs of the THC cigarette. Therefore, present differences in THC concentrations seem to indicate that puff volume of occasional and heavy cannabis users may have differed and that heavy cannabis users needed higher THC concentrations to achieve their desired high.

The current study appears to be the first to compare acute effects of a high THC dose on ERPs in heavy and occasional cannabis users. Our data confirm previous studies in showing that P300 is decreased after cannabis consumption, in occasional as well as heavy cannabis users.
In addition, we found that, at early attentional selection processes, occasional cannabis users show a decreased P100, whereas heavy users have developed tolerance. These findings are in line with the behavioral data that were demonstrated. THC significantly impaired performance of occasional users on the DAT and the SST, whereas heavy users were only impaired on the SST. Therefore, it can be concluded that heavy cannabis users have developed tolerance for some of the effects of THC and that this tolerance is also demonstrated at the level of brain processing, as was shown with the P100.

Acknowledgements This study was supported by a grant from the German Society against Alcohol, Drugs and Driving ("Bund gegen Alkohol und Drogen im Straßenverkehr").

Open Access This article is distributed under the terms of the Creative Commons Attribution Noncommercial License which permits any noncommercial use, distribution, and reproduction in any medium, provided the original author(s) and source are credited.

\section{References}

Böcker KBE, Gerritsen J, Hunault CC, Kruidenier M, Mensinga TT, Kenemans JL (2010) Cannabis with high THC contents affects perception and visual selective attention acutely: an event-related potential study. Pharmacol Biochem Behav 96:67-74

Bolla KI, Brown K, Eldreth D, Tate K, Cadet JL (2002) Dose-related neurocognitive effects of marijuana use. Neurology 59:13371343

Brocke B, Tasche KG, Beauducel A (1996) Biopsychological foundations of extraversion: differential effort reactivity and the differential P300 effect. Personal Individ Differ 21:727-738

Cappell H, Pliner P (1974) Regulation of the self-administration of marihuana by psychological and pharmacological variables. Psychopharmacologia 40:65-76

Coull JT (1998) Neural correlates of attention and arousal: insights from electrophysiology, functional neuroimaging and psychopharmacology. Prog Neurobiol 55:343-361

Curran HV, Brignell C, Fletcher S, Middleton P, Henry J (2002) Cognitive and subjective dose-response effects of acute oral Delta 9-tetrahydrocannabinol (THC) in infrequent cannabis users. Psychopharmacology (Berl) 164:61-70

Duncan-Johnson CC (1981) Young Psychophysiologist Award address, 1980. P300 latency: a new metric of information processing. Psychophysiology 18:207-215

Eldreth DA, Matochik JA, Cadet JL, Bolla KI (2004) Abnormal brain activity in prefrontal brain regions in abstinent marijuana users. NeuroImage 23:914-920

Falkenstein M, Hoormann J, Hohnsbein J (1999) ERP components in $\mathrm{Go} /$ Nogo tasks and their relation to inhibition. Acta Psychol (Amst) 101:267-291

Fillmore MT, Rush CR, Hays L (2002) Acute effects of oral cocaine on inhibitory control of behavior in humans. Drug Alcohol Depend 67:157-167

Fried P, Watkinson B, James D, Gray R (2002) Current and former marijuana use: preliminary findings of a longitudinal study of effects on IQ in young adults. CMAJ 166:887-891

Hall W, Solowij N (1998) Adverse effects of cannabis. Lancet 352:1611-1616 
Hart CL, van Gorp W, Haney M, Foltin RW, Fischman MW (2001) Effects of acute smoked marijuana on complex cognitive performance. Neuropsychopharmacology 25:757-765

Heishman SJ, Arasteh K, Stitzer ML (1997) Comparative effects of alcohol and marijuana on mood, memory, and performance. Pharmacol Biochem Behav 58:93-101

Ilan AB, Smith ME, Gevins A (2004) Effects of marijuana on neurophysiological signals of working and episodic memory. Psychopharmacology (Berl) 176:214-222

Ilan AB, Gevins A, Coleman M, Elsohly MA, de Wit H (2005) Neurophysiological and subjective profile of marijuana with varying concentrations of cannabinoids. Behav Pharmacol $16: 487-496$

Isreal JB, Chesney GL, Wickens CD, Donchin E (1980) P300 and tracking difficulty: evidence for multiple resources in dual-task performance. Psychophysiology 17:259-273

Jodo E, Kayama Y (1992) Relation of a negative ERP component to response inhibition in a Go/No-go task. Electroencephalogr Clin Neurophysiol 82:477-482

Jones RT, Benowitz NL, Herning RI (1981) Clinical relevance of cannabis tolerance and dependence. J Clin Pharmacol 21:143S$152 \mathrm{~S}$

Kanayama G, Rogowska J, Pope HG, Gruber SA, Yurgelun-Todd DA (2004) Spatial working memory in heavy cannabis users: a functional magnetic resonance imaging study. Psychopharmacology (Berl) 176:239-247

Kempel P, Lampe K, Parnefjord R, Hennig J, Kunert HJ (2003) Auditory-evoked potentials and selective attention: different ways of information processing in cannabis users and controls. Neuropsychobiology 48:95-101

Kok A (2001) On the utility of P3 amplitude as a measure of processing capacity. Psychophysiology 38:557-577

Logan GD (1994) On the ability to inhibit thought and action. In: Dagenbach D, Carr TH (eds) Inhibitory processes in attention, memory and language. Academic, San Diego, pp 189-239

Mangun GR (1995) Neural mechanisms of visual selective attention. Psychophysiology 32:4-18

Mangun GR, Hillyard SA (1990) Electrophysiological studies of visual selective attention in humans. In: Scheibel AB, Wechsler AF (eds) Neurobiology of higher cognitive function. Guilford, New York, pp 271-295

Mertens R, Polich J (1997) P300 from a single-stimulus paradigm: passive versus active tasks and stimulus modality. Electroencephalogr Clin Neurophysiol 104:488-497

Moskowitz H (1973) Laboratory studies of the effects of alcohol on some variables related to driving. J Saf Res 5:185-192

Nordstrom BR, Hart CL (2006) Assessing cognitive functioning in cannabis users: cannabis use history as an important consideration. Neuropsychopharmacology 31:2798-2799
Polich J, Kok A (1995) Cognitive and biological determinants of P300: an integrative review. Biol Psychol 41:103-146

Pope HG Jr, Yurgelun-Todd D (1996) The residual cognitive effects of heavy marijuana use in college students. JAMA 275:521-527

Pope HG Jr, Gruber AJ, Hudson JI, Huestis MA, Yurgelun-Todd D (2001) Neuropsychological performance in long-term cannabis users. Arch Gen Psychiatry 58:909-915

Ramaekers JG, Kauert G, Theunissen EL, Moeller MR (2006) Up in smoke: comparability of THC dosing across performance studies. Neuropsychopharmacology 31:2800-2801

Ramaekers JG, Kauert G, Theunissen EL, Toennes SW, Moeller MR (2009) Neurocognitive performance during acute THC intoxication in heavy and occasional cannabis users. J Psychopharmacol (Oxf) 23:266-277

Rigter H, van Laar M (2002) Epidemiological aspects of cannabis use. In: Spruit IP (ed) Cannabis 2002 report. Ministry of Public Health, Brussels

Robbe HJW (1994) Influence of marijuana on driving. Institute for Human Psychopharmacology, University of Limburg, Maastricht

Roser P, Juckel G, Rentzsch J, Nadulski T, Gallinat J, Stadelmann AM (2008) Effects of acute oral Delta9-tetrahydrocannabinol and standardized cannabis extract on the auditory P300 event-related potential in healthy volunteers. Eur Neuropsychopharmacol 18:569-577

Semlitsch HV, Anderer P, Schuster P, Presslich O (1986) A solution for reliable and valid reduction of ocular artifacts, applied to the P300 ERP. Psychophysiology 23:695-703

Smulders FT, Kok A, Kenemans JL, Bashore TR (1995) The temporal selectivity of additive factor effects on the reaction process revealed in ERP component latencies. Acta Psychol (Amst) 90:97-109

Solowij N, Michie PT, Fox AM (1991) Effects of long-term cannabis use on selective attention: an event-related potential study. Pharmacol Biochem Behav 40:683-688

Solowij N, Grenyer BF, Chesher G, Lewis J (1995) Biopsychosocial changes associated with cessation of cannabis use: a single case study of acute and chronic cognitive effects, withdrawal and treatment. Life Sci 56:2127-2134

Taylor MJ (2002) Non-spatial attentional effects on P1. Clin Neurophysiol 113:1903-1908

Theunissen EL, Jonkman LM, Kuypers KPC, Ramaekers JG (2004) Fexofenadine's effect on performance as a function of dose and workload. J Psychopharmacol (Oxf) 18(Suppl):A48

Toennes SW, Ramaekers JG, Theunissen EL, Moeller MR, Kauert GF (2010) Pharmacokinetic properties of delta9-tetrahydrocannabinol in oral fluid of occasional and chronic users. J Anal Toxicol 34:216-221

Wickens C, Kramer A, Vanasse L, Donchin E (1983) Performance of concurrent tasks: a psychophysiological analysis of the reciprocity of information-processing resources. Science 221:1080-1082 